\title{
Epigenética e Psicologia: Uma Possibilidade de Encontro entre o Social e o Biológico
}

\author{
Aydamari João Pereira Faria Junior ${ }^{1}$ \\ Ana Raquel Mendes de Toledo Neris ${ }^{1}$ \\ lara Peixoto de Oliveira ${ }^{1}$ \\ ${ }^{1}$ Universidade Federal Fluminense, Brasil; E-Mail: aydamari@gmail.com; raquel_neris@hotmail.com; peixotoiara.ip@gmail.com.
}

\begin{abstract}
Resumo
O presente artigo tem o objetivo de mostrar a possibilidade da relação entre os campos da psicologia e da epigenética e como considerações secundárias, a possível relação entre psicopatologias - especialmente, a esquizofrenia - e epigenética. Com esse intuito, foram utilizados como base artigos científicos e livros que permeiam os temas da psicologia, psicopatologias, epigenética e esquizofrenia. A partir disso, foi delineado o percurso de formação da psicologia e do campo da epigenética, incluindo a forma como o último pode impactar o primeiro e gerar novas formas de compreensão sobre a prática do psicólogo. Com base nesta revisão, pode-se afirmar que a epigenética possui grande relevância para a psicologia e é capaz de proporcionar uma nova perspectiva para o campo de psicopatologias, seja sobre suas causas ou na constituição de direções de tratamento.
\end{abstract}

Palavras-chave: epigenética; esquizofrenia; psicologia; psicopatologia.

\begin{abstract}
The following article addresses the possibility of affinity between the fields of psychology and epigenetics. It also addresses, as minor considerations, the possible relationship between psychopathologies - especially, schizophrenia - and epigenetics. For this purpose, we reviewed some articles and books that make up the foundation of psychology, psychopathologies, epigenetics and schizophrenia. Next, we outlined the psychology curriculum and the field of epigenetics, considering how the latter can impact the former and introduce new approaches and changes to the psychologist's praxis. Based on this review, it is possible to claim that epigenetics has a great relevance to psychology and it is capable of providing new perspectives to the field of psychopathologies, both on its causes and
\end{abstract} roots or its treatment directions.

Keywords: epigenetics; psychology; psychopathologies; schizophrenia.

\section{Introdução}

A prática do psicólogo, ainda hoje, é amplamente marcada por uma dualidade em sua essência, independentemente da abordagem que se utiliza. Esse aspecto deve-se ao histórico de formação desse ramo das ciências humanas, pois este tentava estabelecer-se como conhecimento científico em um contexto onde a ciência buscava exatidão baseada na imparcialidade do pesquisador. Desta forma, diferentes correntes psicológicas desenvolveram-se a partir de duas escolas fundamentais: estruturalismo e funcionalismo. Devido a estas circunstâncias há, geralmente, uma divisão no modo como os psicólogos abordam as questões em relação às psicopatologias: enquanto uns pensam a partir de uma perspectiva social, outros referemse a esses distúrbios a partir de fatores biológicos. 
Entretanto, o indivíduo acometido por esses transtornos é possuidor de um corpo físico - alicerce estrutural - ao mesmo modo que é afetado pelas relações funcionais que estabelece ao longo da vida. Portanto, pensar o sujeito a partir de uma lógica que inclua estes dois aspectos, abandonando essa divisão epistemológica mencionada, permite à psicologia ampliar as formas de trabalhar sua praxis em amplo sentido, inclusive e principalmente com as psicopatologias.

Noutro campo, aparentemente distante, encontra-se a epigenética: uma área que se dedica, basicamente, ao estudo das modificações genéticas que ocorrem sem alterar a sequência das bases nitrogenadas da molécula de ácido desoxirribonucleico (DNA). A epigenética tem-se constituído como uma importante ferramenta utilizada para compreender como o ambiente em que um organismo se encontra, interage e influencia o funcionamento de seus genes. Desta forma, trata-se de uma importante ferramenta a ser utilizada pela psicologia, visto que também propõe uma lógica interacionista entre aquilo que é estrutural - os genes - e o ambiente. É justamente sobre esta possível interação entre a psicologia e a epigenética que o artigo tratará.

\section{Objetivos e Métodos}

O presente artigo pretende explorar os conhecimentos obtidos no campo da epigenética como forma de repensar a dicotomia classicamente utilizada pela psicologia na consideração das psicopatologias. Com o intuito de contextualizar o leitor sobre essa dualidade a qual se fala, foram utilizados livros que abordam o processo de formação da ciência, visto que estes possibilitam a compreensão dos pressupostos colocados à constituição da própria psicologia. Para demonstrar a relevância da epigenética sobre a maneira que as psicopatologias são abordadas pela psicologia, foi selecionada uma breve revisão bibliográfica sobre epigenética e sua relação com o comportamento (saudável e patológico).

O objetivo é atualizar essa discussão sobre as psicopatologias na psicologia, fomentando a visão de que o ambiente e a (epi)genética são partes igualmente importantes na compreensão das psicopatologias e a partir daí extrapolar as possibilidades que este vínculo tem a oferecer. Neste sentido, considerando que o elenco de psicopatologias é demasiadamente vasto para que sejam todas abordadas, a esquizofrenia será utilizada como referência particular entre estas. Sua escolha é justificada pelas incertezas que rondam suas causas, sua incidência e prevalência em sociedades culturalmente diversas e pela dificuldade em estabelecer formas de tratamento que ofereçam um pleno suporte às potencialidades do indivíduo acometido.

Em relação à busca dos artigos sobre epigenética, esta foi feita utilizando-se combinações das palavras-chave "behavior", "behavioral", "epigenetics", "schizophrenia" e "psychology" ("comportamento", "comportamental", "epigenética", "esquizofrenia" e "psicologia", respectivamente, em português), em bases de dados de artigos indexados e revisados por pares. Destacamos, entre as bases de dados, o Pubmed. Foram encontrados centenas de artigos: em função do escopo deste trabalho, selecionamos aqueles com viés mais "macro", ou seja, menos exclusivamente dedicados aos mecanismos moleculares relativos à relação entre epigenética e comportamento (saudável e patológico). Encerramos a seleção com 30 (trinta) artigos.

\section{Contextualização Histórica}

A ciência é um método de conhecimento do mundo de grande influência nos dias atuais. No entanto, o conhecimento científico teve início a partir do que é chamado de senso comum, ou seja, os conhecimentos que o homem formula a partir de sua própria experiência do dia a dia sem haver, essencialmente, um experimento laboratorial que o comprove. Podem ser citados diversos saberes provenientes desse tipo de conhecimento, como por exemplo, o fato de que muitos indivíduos sabem que o fogo queima sem, necessariamente, terem se queimado ao longo de sua vida, mas a partir de uma informação que lhe é passada por outra pessoa (Siman, 1999, 17).

A partir dessas formulações singulares que mostraram benefícios à sobrevivência do homem, a ciência dedicou-se em compreender os fenômenos do mundo de forma experimental para adquirir maior domínio sobre eles e controlar o impacto destes sobre a vida humana. Conforme Trujillo (1974) "A ciência é todo um conjunto de atitudes e atividades racionais, dirigidas ao sistemático conhecimento com objeto limitado, capaz de ser submetido à verificação" (Marconi \& Lakatos, 2003, p. 80). Portanto, o método científico experimental propõe hipóteses sobre a realidade e examina a validade das mesmas com base em testes realizados sob condições controladas. Essa moderação do ambiente de experimentação é essencial para comprovar o pressuposto apresentado, visto que diferentes fatores vão influir sobre a variável de estudo. Dessa forma, com o controle sobre o experimento é possível manipular repetidas vezes as condições em que uma variável irá se comportar e concluir algo sobre isso, o que se tornará um conhecimento geral validado pelo método científico. 
O caminho percorrido entre a forma de conhecer do senso comum e o método científico experimental foi perpassado por importantes autores, e momentos históricos, ao longo do tempo. Nesse cenário, convém ressaltar o "Século das Luzes" (século XVIII) que propiciou à ciência um lugar de destaque como modo de compreensão do mundo. Todavia, a forma de depreender estes fenômenos por muito tempo desdobrou-se sobre as questões externas ao homem, ligadas à natureza (Siman, 1999, pp. 17-25). Já no século XIX, a ciência se torna ainda mais abrangente e uma nova questão é colocada:

“Por que então não aplicar seus princípios e seu método aos demais domínios da atividade humana, no campo do saber relativo ao homem social, por exemplo? Sobretudo porque esses progressos são, por outro lado acompanhados de vários problemas sérios no plano social, o que seria oportuno solucionar logo que possível. " (Siman, 1999, p. 25)

A proposta do homem de conhecer a si, e entender seu agir no mundo, já estava colocada pela filosofia desde a Grécia Antiga e indagava-se principalmente sobre os aspectos éticos, morais e políticos do ser humano. É no contexto do século XIX que emergem as ciências humanas, as quais buscam compreender o próprio homem e legitimar esse conhecimento pelo método científico, como por exemplo, a antropologia, sociologia e psicologia (Siman, 1999, pp. 22-25). Cada um desses campos de estudo possui diferentes perspectivas para pensar a relação entre o homem e o meio no qual esse vive.

Desde o princípio, as diferentes áreas das ciências humanas defrontaram-se com uma dificuldade em comum: estabelecer-se como conhecimento científico devido a dualidade entre objeto e pesquisador. Isso porque, o método de produção da ciência é claramente definido no que diz respeito a separação entre pesquisador e o objeto da pesquisa. No âmbito das ciências naturais pode-se ter essa divisão, ainda que hoje seja reconhecido que toda pesquisa está sobre um recorte histórico, ou seja, possui limitações relacionadas ao contexto espaço-temporal no qual é realizada. Além disso, contém delimitações feitas pelo próprio pesquisador que agora não é visto como totalmente imparcial ao objeto, mas que, no entanto, deve descrever nitidamente seus objetivos no próprio projeto para que este mantenha sua cientificidade. Contudo, as ciências humanas e sua problemática em ter o homem enquanto objeto e pesquisador de forma concomitante, por muito tempo buscou enquadrar-se nessa ciência que à época buscava total imparcialidade nessa relação (Souza, \& Albuquerque, 2012, pp. 110-111).

A psicologia, que começou a se desenvolver por volta de 1875, foi marcada por essa perspectiva de ciência que buscava ampla neutralidade. Com isso, ao longo do tempo diferentes pesquisadores desenvolveram diversas teorias na tentativa de definir um objeto específico para garantir um status científico a esse campo. É importante ter consciência deste processo de formação da psicologia para então compreender a relação existente entre o que é funcional e estrutural, características essenciais para o entendimento do impacto da epigenética - que será abordada mais adiante - sobre a psicologia e, particularmente, as psicopatologias.

A história da psicologia, na chamada psicologia clássica, compartilha de três momentos relacionados à, principalmente, três nomes, Wilhelm Maximilian Wundt (1832-1920), Edward Bradford Titchener (1867-1927) e William James (1842-1910). Estes são pilares para o desenvolvimento da psicologia e de pensamentos que constituem na atualidade o fazer psicológico. Com o convívio institucional comum aos nomes citados houve a classificação de duas escolas, Estruturalistas e Funcionalistas.

É comum em obras que relatam a historicidade e o desenvolver da psicologia a afirmação de que Wundt (1832-1920) foi seu fundador, ainda que antes dele já houvesse outros laboratórios e outras pessoas que pensavam sobre a psicologia.

Isto acontece porque Wundt apresenta a psicologia sendo estudada no ambiente laboratorial, no qual propõe um objeto de estudo específico, o que confere à Psicologia seu status de ciência. Ele fundou o Laboratório de Psicologia na Universidade de Leipzig, na Alemanha, mas para além deste espaço físico elaborado existem conceitos que foram criados por ele e fizeram com que este homem fosse tão lembrado na construção do que se tem hoje como Psicologia. Um conceito desenvolvido por Wundt é o de que a experiência de um indivíduo quando analisada comporta um conteúdo objetivo - experiência mediata - e um conteúdo subjetivo - experiência imediata. A partir disso, definiu a psicologia como "uma ciência empírica cujo objeto de estudo é a experiência imediata". Ou seja, diante de um contexto histórico em que muito se falou sobre mente e alma, a psicologia de Wundt é apresentada estudando somente a experiência que um sujeito tem ou passa, sendo essa um conjunto de processos que se interligam. Assim, se fez clara a ideia de que não existe uma diferenciação de natureza dentre os campos interno e externo, porque a experiência permeia ambos, o que se difere é a maneira como se aborda a experiência. Em outras palavras, a psicologia e as ciências da natureza, o imediato e o mediato; o corpo e o conteúdo subjetivo se relacionam pela complementaridade (Araujo, 2011, pp. 93-96).

Concomitante ao desenvolver de Wundt, Titchener, seu aluno no laboratório em Leipzig, pensou o Estruturalismo para psicologia. Este conceito se difundiu no século XX e influenciou o que estava sendo produzindo neste momento da história com o conceito de estrutura. Para Titchener, a estrutura é um sistema composto por elementos e relações que estão submetidos a 
uma lei que regula estas relações. Por exemplo, Jean Piaget é considerado um estruturalista, isto porque em todo o seu pensamento sobre o desenvolvimento do ser humano existem duas leis, Lei da Assimilação e Lei da Acomodação que, como na definição, permanecem em todos os estágios descritos na teoria piagetiana. Ou seja, há no Estruturalismo uma nova demarcação do objeto de estudo que continua o mesmo que em Wundt, mas direcionado à "decomposição em seus elementos (abordagem estrutural, mais semelhante à anatomia)" (Araujo, 2011, pp. 102-103).

"Titchener foi reconhecidamente um defensor do elementarismo e do associacionismo. A análise ou decomposição dos processos psíquicos conscientes em seus elementos mais básicos (estruturas fundamentais) e a descoberta dos seus mecanismos associativos subjacentes eram os objetivos últimos de sua psicologia estruturalista" (Araujo 2011, p. 103).

O contexto histórico inclui um nome que influenciou diretamente a escola do Funcionalismo, e outras áreas de pesquisa do século XIX, Charles Darwin (1809-1882). Sua influência é considerável e isto se comprova no período histórico dapublicação do livro Origem das Espécies (1859), chamado de 'era darwiniana'. O contato da biologia expressa nos trabalhos de Darwin com a psicologia acontece quando esse começa a pensar sobre a existência do homem a partir de um ser já existente. E então nos livros $A$ ascendência do homem (1871) e $A$ expressão das emoções em homens e animais (1872) o autor elabora teses sobre a relação da estrutura corporal e as variações das faculdades mentais. Com isso, os conceitos de seleção e adaptação já apresentados em seu primeiro livro são utilizados na constituição do Funcionalismo.

"[...] graças ao empuxo darwinista, demarca-se uma psicologia interessada na adaptação, evolução e variação das atividades mentais. Contudo, ao longo da história da psicologia, esse modelo se dissemina, transcende os seus movimentos originais e se dissolve no campo psicológico, dando a uma expressiva parte desse campo sua feição atual enquanto saber voltado para as práticas de ajustamento." (Ferreira \& Gutman 2011, p. 122)

Então, na passagem do século XIX para o século XX, James nos Estados Unidos, escreve sobre as funções de um organismo possuidor de psiquismo, "o que um organismo é ou deixa de ser, decorre das funções que exerce e das interações com um dado ambiente" (Ferreira \& Gutman, 2011, pp. 128). A partir disso, conceitua alguns princípios para o Funcionalismo: assistem aticidade, função e adaptação. O princípio da assistematicidade é porque a psicologia funcional se remete a diversidade do saber psicológico; a função determina o que se estuda, não mais os elementos mentais são estudados, mas as suas funções são verificadas; e a adaptação relata uma nova forma de explanação da consciência, mesmo através da introspecção, esclarecendo que a consciência é adaptada, mas também adaptante (Ferreira \& Gutman, 2011, P. 134). E para uma melhor compreensão, atentando-se para o conceito de adaptação, entende-se que o sujeito se ajusta ao meio social em que ele está inserido e que este sujeito é um "meio de promoção de uma utilidade, no caso, a social” (Ferreira \& Gutman, 2011, p. 137). É devido a essa relação - dentre outros conceitos - do ser com o ambiente que é possível dizer que a Epigenética possui princípios funcionalistas, pois é através do meio que o psicólogo atua promovendo, também, a utilidade; atuando assim no indivíduo para além de leis gerais.

“A psicologia funcional conduziria a uma concepção instrumental do ser humano. [...] o homem não seria mais uma inteligência servida de órgãos, mas uma mera consciência a serviço destes. Desta maneira, o homem é apenas um dentre os seres vivos e a consciência somente um órgão, ainda que especial, no seu ajuste ao meio natural-social." (Ferreira \& Gutman, 2011, p. 137)

Ao entender-se as escolas e o início do desenvolver da psicologia é possível pensar a epigenética como área influenciada pelo funcionalismo. Contudo, como nas diversas áreas da psicologia, não é possível pensar em uma perspectiva de pesquisa que isole essas escolas, visto que, o ser humano possui um corpo físico, ou seja, estrutural e o mesmo está sempre em constante interação com o meio no qual vive, estabelecendo relações funcionais. Como já dito, o estruturalista estuda o "anatômico" enquanto o funcionalista analisa o "fisiológico" e estas duas áreas são interligadas e permeáveis. Para elucidar essa afirmação é possível exemplificar a tese de Piaget, autor citado anteriormente. Ainda que este seja considerado um estruturalista, pois centraliza sua teoria na definição de fases de maturação orgânica pelas quais o sujeito age no ambiente de modo a se adaptar, em busca do equilíbrio, pode-se se encontrar também a presença do funcionalismo (Präss, 2012, p. 13-16), na medida em que:

"Segundo Piaget, o conhecimento não pode ser concebido como algo predeterminado desde o nascimento (inatismo), nem como resultado do simples registro de percepções e informações (empirismo): o conhecimento resulta das ações e interações do sujeito no ambiente em que vive. Todo conhecimento é uma construção que vai sendo elaborada desde a infância, por meio de interações do sujeito com os objetos que procura conhecer, sejam eles do mundo físico ou do mundo cultural. O conhecimento resulta de uma inter-relação do sujeito que conhece com objeto a ser conhecido." (Moreira, 1999, p. 75) 
Diante disso, a epigenética surge como um importante campo de estudo a ser explorado pela psicologia, isso porque evidencia o elo existente entre os fatores genéticos - estruturais - e o ambiente - lugar, seja este físico ou social, de interação do indivíduo onde este constrói suas relações funcionais.

\section{Epigenética}

São Para compreender os princípios da epigenética faz-se necessário conhecer o campo da genética, um ramo da ciência que estuda, em resumo, as bases da hereditariedade. (Motta, 2005, pp. 2-3). O vocábulo gene é o radical para várias palavras desta área de estudos da biologia e conhecer esses conceitos é essencial para o entendimento do modo pelo qual os mecanismos epigenéticos atuam. $O$ genoma diz respeito a todo o material genético herdado por um indivíduo, seja este responsável pela codificação (éxons) de proteínas, ou não (íntrons). De acordo com o " 'Dogma Central' da biologia molecular [...] genes são unidades funcionais do DNA, e a função usual de um gene é especificar a estrutura de uma proteína" (Read \& Donnai, 2009, p. 55), sendo o conjunto desses genes denominado como genótipo. Conforme a genética clássica, fundada no início do século XX, esses genes determinam a manifestação de características observáveis - como, por exemplo, traços físicos e comportamentais e essa exteriorização gênica é chamada de fenótipo. Desta forma, salvo raras exceções (onde a penetrância de determinados genes é menor que $100 \%$ ), a presença de um gene (ou alelo) em particular seria suficiente para a manifestação da (s) característica (s) associada (s) a este alelo.

“O DNA é composto por unidades chamadas nucleotídeos. Cada nucleotídeo, por sua vez, é constituído por uma base nitrogenada, uma pentose e um fosfato." (Motta, 2005, p. 15). As bases nitrogenadas (adeninas, guaninas, citosinas e timinas) ligam-se verticalmente por meio de ligações entre suas pentoses, formando uma fita. "Horizontalmente", ou seja, entre as fitas, ligam-se por meio de pontes de hidrogênio que ocorrem entre as bases nitrogenadas guanina - citosina e adenina - timina), formando a dupla hélice que constitui, ao fim e ao cabo, os cromossomos. É a sequência de nucleotídeos que, resumidamente, chamamos de "código genético". Esse arcabouço é semelhante no ácido ribonucleico (RNA): filamentos únicos que têm sua sequência determinada por segmentos do DNA, a partir do qual o RNA é transcrito, e irão efetivamente determinar a constituição das proteínas.

Um fator importante na história da genética é o sequenciamento do genoma humano, quando diversas respostas sobre os genes e suas funções foram obtidas. Por exemplo, até então acreditava-se que havia uma centena de milhares de genes; o projeto genoma identificou pouco mais de 20.000, trazendo à tona uma grande demanda por explicações e atualizações sobre como organismos complexos como o humano podem operar com "poucos genes". Para além disto, outras descobertas confirmaram e expandiram a correlação entre determinadas conformações genéticas (localização dos genes) e as manifestações fenotípicas das características ligadas a tais genes. De forma indireta, o projeto genoma reafirmou a demanda por uma organização precisa da molécula de DNA: uma molécula com pouco menos de dois metros de comprimento só pode manter-se ativa e íntegra em um espaço intracelular microscópico exíguo apenas por meio de estratégias de compactação de altíssima eficiência. No entanto, para que os genes se expressem necessita-se que estes se tornem acessíveis ao processo no qual codificam peptídeos que, por sua vez, serão responsáveis por ações expressas no fenótipo. Como os genes ativos necessários ao longo do ciclo de vida de uma célula são variáveis, os cromossomos são remodelados, função realizada primariamente pelas histonas, proteínas que se especializaram nesse papel fundamental aos organismos vivos (Figura 1). Para explicitar esse processo, pode-se fazer uma correlação a um carretel de linha:

“Fazendo uma analogia, imaginem o carretel sendo as histonas, e a linha sendo a molécula de DNA. Se agora imaginarmos que o DNA (a linha do carretel) é composto pelos genes, e que muitos dos genes precisam ser expressos (ou seja, eles precisam decodificar suas sequências na forma de proteínas, que efetivamente são as moléculas que fazem as células funcionarem), se o DNA permanecesse totalmente enrolado, os genes não seriam capazes de serem expressos na forma de proteínas" (Fantappie, 2013, p. 2) 


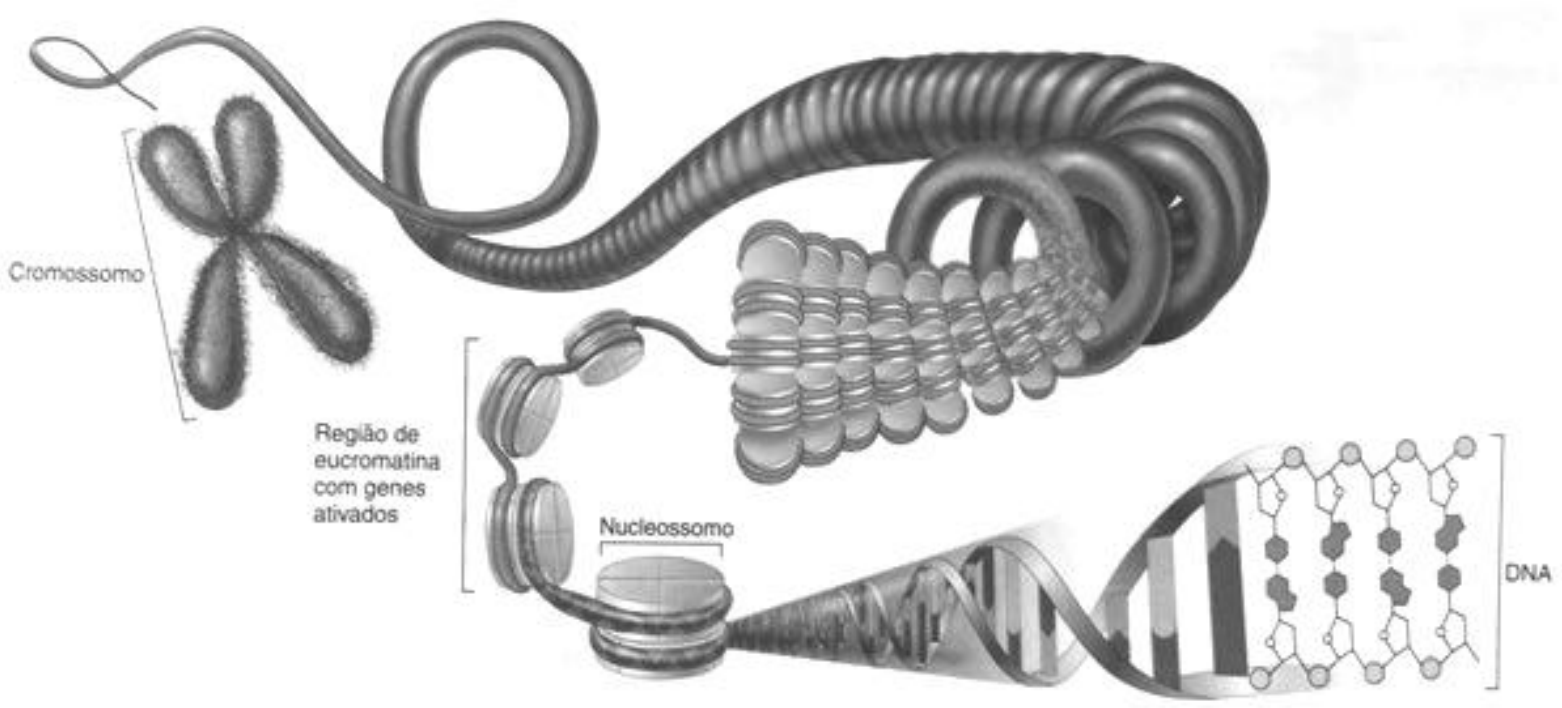

Figura 1. Representação esquemática do material genético: Parte do DNA se enrola em torno de complexos de histonas, formando estruturas conhecidas como nucleossomos (De: Fox SI, Fisiologia Humana, 2007)

A apresentação das concepções acima permite introduzir o conceito de epigenética. Esse termo foi criado pelo biólogo Conrad Waddington, por volta de 1940, que "tinha como objetivo construir uma ponte, inédita até então, entre os fenômenos observados no desenvolvimento de um organismo e sua constituição genética" (Freitas-silva \& Ortega, 2014, p. 769). A partir disso, ele definiu a epigenética como "o ramo da biologia que estuda as interações causais entre os genes e seus produtos, os quais trazem à tona o fenótipo" (Jablonka \& Lamb, 2002, p. 83). No entanto, suas suposições sobre o tema eram apenas teóricas, pois à época ainda não havia estudos experimentais na área. Nesse contexto, a própria biologia não se desdobrava sobre a vinculação entre os campos do desenvolvimento e da genética (Freitas-Silva \& Ortega, 2014, p. 769).

Ao decorrer das décadas, houve um demasiado aumento nesse campo de pesquisa demonstrando, inclusive experimentalmente, a validade da proposta que Waddington havia colocado bem no princípio de seus estudos sobre o tema. Atualmente, pode-se delinear a epigenética como um ramo que estuda como a interação entre o ambiente e os genes do indivíduo levam a impressão de novas características sobre o conteúdo genético, sem causar alteração na sequência de bases do DNA. Essas particularidades acrescentadas sobre o conteúdo genómico podem gerar alterações fenotípicas e colocam em questão a definição clássica de genes, visto que, a partir dos mecanismos epigenéticos pode-se haver alterações fenotípicas que antes eram consideradas como fatídicas e determinísticas, ou seja, que não eram afetadas pelas interações que o indivíduo estabelece. Portanto, com a epigenética um processo que era pensado numa única via amplia-se para uma relação em que o estrutural (os genes) e o funcional (o ambiente) se permeiam constantemente. Essa elucidação sobre o papel da epigenética é observada no recente editorial publicado no jornal científico Current Neuropharmacology:

"O campo revolucionário da epigenética [...] tenta explicar os mecanismos pelos quais os fatores ambientais interagem com o esqueleto básico das sequências genômicas para dar origem a um fenótipo em particular. A beleza das mudanças epigenéticas é que, embora elas sejam suficientemente estáveis em um indivíduo, são dinâmicas e moduladas em resposta a vários estímulos externos (ambientais) e internos (internos ao corpo); além disso, elas podem ser passadas às futuras gerações com ou sem modificações" (Bókkon \& Mallick, 2016, p. 2).

As alterações epigenéticas podem ocorrer por meio de diferentes mecanismos. Como já dito, o fenótipo apresentado por qualquer indivíduo está relacionado ao modo como os genes se estruturam. Dessa forma, determinadas conformações no material genético irão permitir que uma característica fenotípica seja manifestada enquanto outras não, o que é chamado, respectivamente, de expressão e silenciamento genômico. Segundo a corrente clássica da genética essa organização é regulada pela própria molécula de DNA da forma como foi herdada. Porém, com a perspectiva dinâmica da epigenética, vê-se que esse alicerce herdado pode ser "transformado" no decorrer do tempo. Tal qual um livro que, relido, muda seu significado mesmo possuindo as mesmas letras, a epigenética é capaz de mudar o conteúdo expresso pelos genes sem mudar as letras (os 
nucleotídeos) do código genético. Diante disso, a reversibilidade dos traços herdados ou daqueles adquiridos através da relação "genes x ambiente" e a capacidade de passá-los às novas gerações têm sido o foco dos estudos nesse campo.

Em relação aos mecanismos epigenéticos, embora já existam numerosas investigações, ainda não há uma definição exata sobre a função de cada um deles. Esse fato não se deve estritamente à quantidade de informações que se tem sobre o tema, mas, principalmente pelo dinamismo presente na epigenética. Diferentes alterações químicas podem ocorrer na estrutura do DNA ainda que não alterem sua sequência de bases nitrogenadas. Revisando a literatura, podem-se destacar alguns mecanismos que têm guiado os estudos que buscam compreender o funcionamento deste campo.

Dentre os meios que podem causar variações na expressão gênica e consequentemente fenotípica, podem-se destacar transformações químicas que podem ocorrer no DNA. As principais alterações químicas destacadas são a metilação e a acetilação, em cada um destes casos, "o genoma é marcado pela adição de grupos químicos que influenciam a atividade genética sem efetivamente mudar a informação codificada na molécula de DNA" (Moore, 2017, p. 2). Os locais em que cada uma dessas ligações ocorre e seus efeitos ainda não estão completamente delimitados, visto que o meio nuclear é demasiadamente dinâmico e ainda relativamente desconhecido. Dessa forma, as metilações e acetilações não ocorrem de maneira isolada e com o controle sobre uma característica pontual, mas se dão de forma simultânea impactando umas às outras. Apesar da dificuldade de demarcação funcional desses mecanismos, diferentes pesquisas e experimentações têm trazido indícios sobre a forma de funcionamento destes. Um aspecto evidente dentre esses estudos é de que esses processos, em geral, são verificados especificamente em regiões de controle da atividade gênica, ou seja, que determinam a expressão ou silenciamento genômico.

Para elucidar esse processo de expressão ou repressão gênica, pode-se abordar um outro mecanismo epigenético que também é afetado por essas alterações químicas, o remodelamento que é feito pelas histonas:

“[...] diferentes genes são expressos em diferentes momentos e, naturalmente, estão localizados em diferentes regiões da molécula de DNA (ou nos cromossomos). Nesse sentido, partes da molécula de DNA são constantemente desenroladas e enroladas (o que se conhece por "remodelamento dos cromossomos", ou "da cromatina")" (Fantappie, 2013, p. 2)

Essas alterações dependem essencialmente das condições químicas do ambiente intracelular, ou seja, sinalizações desse tipo vão definir a função das histonas num determinado momento. As células de um organismo possuem características próprias a cada um, pois se estruturam a partir do conteúdo genético; contudo, essas também são afetadas constantemente por sinais vindos do ambiente, o que nessa perspectiva inclui também o próprio corpo, onde fatores ambientais internos (e.g. hormônios, citocinas, linfocinas...) e externos (e.g. nutrição e exposição hormonal materna) determinam o padrão de diferenciação das células embrionárias (ou potentes) ao longo do desenvolvimento (músculos, ossos ou neurônios) intra e extrauterino. Dessa forma, torna-se clara a atuação da epigenética sobre a expressão gênica, posto que o ambiente é capaz de alterar os sinais químicos que serão recebidos pela célula e, consequentemente, modificar a forma como as histonas realizam o remodelamento do material genético.

Outro mecanismo de regulação epigenético está relacionado aos RNAs não codificantes. Estas moléculas podem interferir na função dos RNAs mensageiros, responsáveis pela codificação de proteínas relacionadas às características específicas de um determinado indivíduo. Esses trechos não codificantes podem interferir na expressão gênica na medida em que são capazes de bloquear ou modificar a forma pela qual os RNAs mensageiros irão se expressar. A importância desse mecanismo e a sua atuação pode ser encontrada no trecho abaixo. 

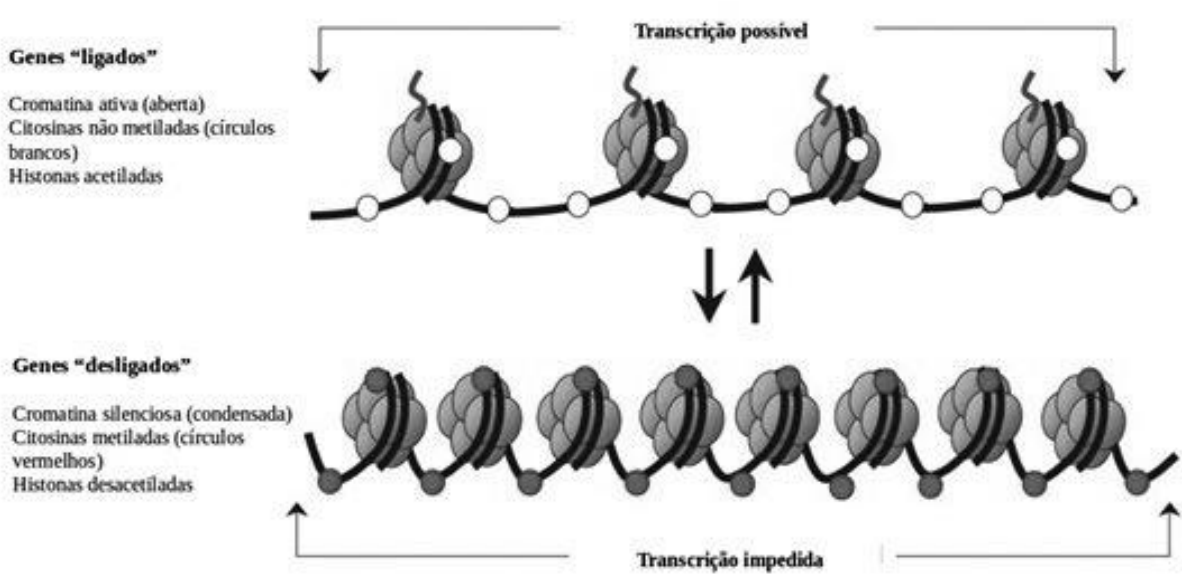

Figura 2. Representação esquemática das alterações epigenéticas e seus impactos sobre a transcrição. (Adaptada de: http://www.epibeat.com/wp-content/uploads/2013/03/3.png)

“Um terceiro mecanismo de regulação epigenética foi recentemente descoberto em mamíferos através da descoberta de três classes de pequenos fragmentos não codificantes (não traduzidos em proteínas) de RNA, conhecidos como microRNA, importantes para a expressão e silenciamento gênicos (Berezikov, Cuppen, \& Plasterk, 2006). Por exemplo, uma classe de pequenos RNA conhecidos como siRNA (pequenos RNA de interferência) podem se ligar a sequências complementares de RNA mensageiro, suprimindo sua tradução a peptídeos e proteínas. Os microRNA agem junto com a metilação do DNA e da remodelagem da cromatina na regulação da expressão gênica (Saetrom, Snøve, \& Rossi, 2007)" (González-Pardo \& Álvarez 2013, p. 7).

Os mecanismos enumerados constituem os principais meios que têm sido estudados pela epigenética na tentativa de estabelecer uma maior compreensão sobre estes fenômenos. Um outro item importante abordado por este campo é o entendimento sobre a capacidade de reversibilidade e herança dessas variações genéticas. Já há algum tempo, tem-se estudado a capacidade de transmissão dessas características adquiridas através dos mecanismos epigenéticos e, atualmente, há evidências sobre essa herança conhecida como não-genética ou epigenética. Ao contrário das alterações do genoma, que ocorrem lentamente por mutações aleatórias ao longo da história, essas alterações epigenéticas podem ser passadas rapidamente, pois estão o tempo todo sobre influência direta do ambiente, permitindo que um indivíduo se adapte às condições ambientais às quais está exposto (Fantappie, 2013, p. 4).

“Por exemplo, experiências vividas pelos pais (dieta, maus tratos, tratamento hormonal) podem ser transmitidas para as gerações futuras. Isso tem sido bem demonstrado em uma série de estudos onde famílias com grave escassez de alimentos na geração dos avós, filhos e netos têm maior risco de doenças cardiovasculares e diabetes. Outros estudos sugerem que as mães passem aos filhos os efeitos cognitivos durante a gestação, provavelmente liberando hormônios que fazem com que marcadores químicos epigenéticos (não dependentes dos genes) apareçam nos genes de seus filhos, regulando sua expressão depois do nascimento. Outro exemplo claro do papel da herança epigenética pode ser encontrado nos gêmeos idênticos; estudos mostram que durante a transição da infância para a vida adulta, os gêmeos passam a divergir significativamente em seus níveis de sintomas relacionados à ansiedade e à depressão. Como compartilham do mesmo background genético (exatamente a mesma sequência de bases em ambos os genomas) essa divergência só pode ser fruto das experiências individuais durante a vida (e das mudanças epigenéticas)" (Fantappie, 2013, p. 4). 


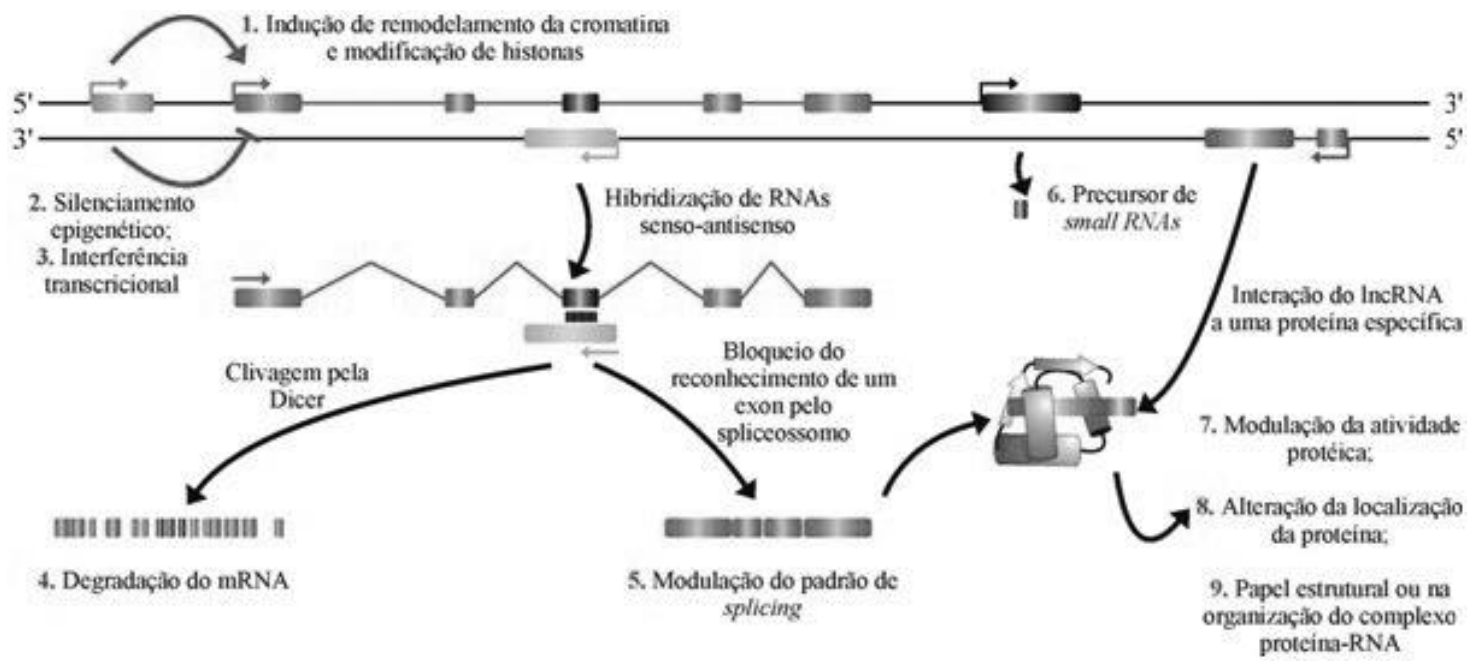

Figura 3. Representação dela atuação de mecanismos epigenéticos. (De: https://imgur.com/QbPIW7X. Acesso em 31 de maio de 2017).

\section{Psicopatologias e Epigenética}

Para Analisando o percurso decorrido até então, pode-se salientar que o estudo da epigenética pode apresentar uma saída ao clássico maniqueísmo do genético sobre o social e vice-versa, criando uma nova possibilidade de compreensão de diversos fenômenos que dizem respeito ao comportamento e, também, à qualidade de vida do homem. Dentre estes fenômenos, salientamos aqueles que eventualmente terminam por marginalizar (stricto sensu) parte da sociedade, ou seja, as psicopatologias.

É prudente lembrar que mesmo a "patologização" pode e deve ser discutida em diversos campos, inclusive na esfera da "invenção (social) da doença" (Carneiro, 2002). No entanto, há limites para tais discussões. Este limite, até então, era dado com respaldo da genética, absoluto e determinístico: há alterações e patologias (geneticamente) indiscutíveis: hemofilia, doença de Huntington, daltonismo, entre outras. A epigenética, por sua vez, retira parte do peso do "destino inexorável" de alguns diagnósticos, fornece esperança e participação individual no tratamento e mesmo na prevenção de determinadas patologias. A título de exemplo, um paciente diabético tinha, há menos de 30 anos, no momento do recebimento de seu diagnóstico, um "fardo" extra a carregar. Hoje sabemos que há variações da doença que podem ter controle considerável com medidas ambientais (e.g. dieta e atividade física), muitas vezes prescindindo parcial ou completamente do controle medicamentoso. 0 fardo familiar dos diagnosticados também mudou e é possível hoje, através das mesmas medidas, contribuir para postergar o aparecimento de quaisquer sintomas ou mesmo até evitá-los usando as mesmas medidas, neste caso profiláticas. Quando a epigenética, permite pensar os transtornos psíquicos para além de fatores genéticos pré-determinantes vê-se o importante papel que pode desempenhar em relação às diversas dimensões das psicopatologias. Ao incluir o ambiente, as relações sociais e as condições físicas do meio no qual o sujeito vive, além de seu arcabouço genético, a epigenética expande o processo de formação ao longo de sua história individual. A preocupação com o reducionismo dos transtornos psíquicos a fatores biológicos e uma perspectiva da atuação da epigenética sobre esses distúrbios podem ser observados no livro Neuropsicologia teoria e prática, mais especificamente no capítulo sobre Neuropsicologia molecular:

"Convém ressaltar, no entanto, que, nessas situações, estamos lidando com cenários de alta complexidade, e não há como sonhar, por ora, que determinado gene ou seu polimorfismo impacte isoladamente a atenção, memória e os demais quesitos neuropsicológicos. Porém, podemos pensar que muitas funções neuropsicológicas e quadro neuropsiquiátricos podem ser também alterados ou regulados por determinados polimorfismos genéticos, bem como pelo meio ambiente e por determinadas condições psicossociais, que por sua vez, podem modificar ainda mais as funções neuropsicológicas, mediante certas alterações genéticas ou epigenéticas, regulando justamente a relação entre meio ambiente e genética da neuropsicologia e dos transtornos neuropsiquiátricos" (Fuentes et al. 2014, p. 47)

Sendo assim, a partir da epigenética pode-se pensar em um dinamismo estabelecido entre o aparato biológico do indivíduo, sua estrutura, e as relações que o mesmo estabelece no decorrer de sua vivência. Pensar uma psicologia a partir dessa perspectiva 
implica considerar ambos os aspectos (genética e ambiente) como base para a compreensão da causa dos transtornos mentais, ampliando o campo referente a possibilidade de diagnóstico e, ainda, permitindo repensar as formas de tratamento e intervenção a serem trabalhadas com os sujeitos acometidos por psicopatologias. Apesar de não ser abordado utilizando termos como epigenética, o caso clínico abaixo retirado do livro Além da Inteligência - Aprendizagem mediada e a capacidade de mudança do cérebro, pode ser usado como uma extrapolação da aplicação dos princípios epigenéticos na atuação do psicólogo:

"Y. veio a mim com uma disfunção muito severa. Ela tinha feição "de pássaro", com olhos saltados, um nariz longo, e tendência de torcer o rosto para os dois lados para focar visualmente. Ela não só não falava, mas também não tinha habilidade de produzir sons que não um grito agudo que não parecia estar relacionado com uma experiência de um estímulo externo a qual havia sido exposta. Era impossível ensiná-la como colocar a língua para fora. Ela sofria de apraxia - uma disfunção marcada pela inabilidade de realizar determinados movimentos físicos como a imitação. Ela também sofria de abulia - inabilidade de iniciar ações por si mesma. Ou seja, ela precisava receber força de uma fonte externa para realizar uma ação. Por exemplo, para que ela levantasse um copo, alguém precisava pegar sua mão e fazê-la agir. Sem isso, ela pararia a ação no meio.

Quando comecei o exame, parecia que nada poderia ser feito, eu desisti. Não acreditava que algo pudesse ser alterado. Mas a mãe, que estava muito infeliz, não desistiu. Ela tinha uma grande necessidade: 'Eu vim até você porque achei que você podia ajudar. Você ajudou a tantos outros. Não consigo aceitar que minha criança será idiota! Se você não pode fazer, me ensine que eu faço!'

Ela veio até mim ano após ano, diversas vezes para receber instruções de como trabalhar com a filha. Após três anos e meio ela trouxe a filha e disse: 'Ela está lendo!'. Eu tratei as palavras da mãe com ceticismo e pensei comigo mesmo: 'Outro sonho de uma mãe que deseja muito um pensamento desejoso'. Mas a mãe trouxe um quadro com letras e a menina as organizou com uma mão, em palavras, frases e assim por diante. Apesar de ter ensinado para a mãe como trabalhar com Y., eu não conseguia acreditar! Eu tive que admitir que para mim foi um tapa na cara, visto que eu havia me perguntado o que teria acontecido se eu tivesse acreditado que era possível alterar a condição da menina e tivesse trabalhado com ela diretamente. Comecei a trabalhar diretamente com ela. Sentamos com Y. ao lado de um computador e ela alcançou níveis incriveis de escrita nele.

Ela escreveu uma maravilhosa biografia, e vimos que ela entendia tudo o que era dito ao redor dela, toda a falta de esperança dita sobre ela. Quando perguntei porque a mãe dela segurava sua mão enquanto digitava, ela respondeu: 'Honrado e respeitado professor...' - e eu senti a ironia de suas palavras - 'se você tivesse sido como eu, e se tivessem dito a você que era incapaz de qualquer coisa, e apenas sua mãe acreditasse em você e a levasse a fazer coisas como minha mãe fez, você também não abriria mão dela, Sr. Professor"' (Feuerstein, 2014, pp. 40-41).

No exemplo acima fica evidente a relação entre os estímulos do ambiente e a estrutura de um organismo: a estimulação incansável promovida pela mãe agiu sobre um arcabouço fisiológico (desde o nível submolecular, genético, ao nível de sistemas neuronais dedicados à memória e aprendizado) alterado, patológico. Uma estimulação ordinária - quiçá uma estimulação "extraordinária qualquer" - não seria capaz de reverter a patologia. Foi a influência ambiental adequada que agiu sobre o arcabouço orgânico para "reverter" tal quadro.

Nessa situação, apresenta-se características próprias a uma constituição genética herdada, porém a capacidade de desenvolvimento e atuação deste indivíduo não se mantém limitada através de um diagnóstico que apenas classifica e não permite explorar condições favoráveis ao bem-estar do sujeito. Ainda que de maneira distante e francamente extrapolada, podemos depreender que mecanismos epigenéticos relativos à estimulação do paciente influencie sua resposta, aumentando mecanismos plásticos cerebrais. Desta forma podemos implicar que a epigenética permite que se trabalhe as relações que um indivíduo estabelece com seu meio de modo a beneficiá-lo, podendo imprimir sobre o conteúdo estrutural as mesmas formas de funcionamento e organização que fazem parte da produção desse bem-estar.

De maneira mais direta, muitas patologias fogem de conceito de relação direta e inequívoca entre "alteração genética e acometimento". Da ansiedade à depressão, passando pela esquizofrenia e pela drogadição, a ideia de uma associação causal entre genes e alelos defeituosos com suas patologias respectivas não é trivial. Isso levou, nos últimos anos, a pesquisas que tentam entender como a presença ou ausência de uma "susceptibilidade genética" é influenciada pelo ambiente, de modo a contribuir para (ou contra) a manifestação de seus sintomas (Mahgoub, \& Monteggia, 2013; Kendler, 2013). Há dados em animais e humanos correlacionando experiências estressantes em diferentes momentos do ciclo de vida (pré-natal, intrauterino e pós-natal recente) com alterações epigenéticas que se traduzem em morfofisiológicas em diferentes áreas do sistema nervoso e em maiores probabilidades de desenvolvimento de patologias psiquiátricas na vida adulta (Nieto, \& cols. 2016; Keverne \& 
cols., 2015; Crews D. 2008). Os efeitos da exposição precoce a drogas (lícitas e ilícitas) e seus efeitos sobre o comportamento também têm sido alvo de investigações epigenéticas (Peña e cols., 2014), bem como a tentativa de compreender os mecanismos centrais do uso e abuso de psicoativos (Nestler, 2013).

O racional por trás destes novos estudos inclui uma nova premissa às ciências do comportamento: a de que tais exposições (a estresse ou psicoativos, por exemplo) têm papéis ativos na “produção" da patologia, alterando as expressões gênicas de receptores, enzimas e neurotransmissores. Além de fornecer possíveis novas abordagens terapêuticas no futuro, tais propostas contribuem para a destituição ou minimização do rótulo de ser doente e contribuem para olhares mais dinâmicos, para um "estar doente".

\section{Esquizofrenia}

A esquizofrenia, termo criado por Eugen Bleuler (1911-1950), tinha como função definir a uma "ruptura de realidade, causada por uma desorganização de várias funções da mente, de tal modo que os pensamentos e os sentimentos não mais trabalhassem juntos normalmente" (Carlson, 2002, p. 528). Acredita-se que aproximadamente 1\% da população mundial é acometida por esta psicopatologia que, segundo os registros, é muito antiga e atinge pessoas de diferentes ambientes e culturas. Existem duas categorias de sintomas que podem ser identificados, os sintomas positivos e os sintomas negativos, essa nomenclatura não se refere a bons ou maus sintomas, mas sim porque os positivos se fazem presentes e os negativos dizem de uma ausência de comportamentos normais (Carlson, 2002, p. 529). Os sintomas positivos são distúrbios de pensamento - pensamentos desorganizados; dificuldade de manter uma ordem lógica, indiferenciando pensamentos plausíveis de incoerentes; alucinações, em que as mais comuns são as alucinações auditivas, que é a percepção de sons que não estão presentes no ambiente; e o delírio, crença em fatos que são falsos e não possuem fundamento. Os sintomas negativos são afalta de iniciativa, de vontade ou de permanência em atividades diárias e a ausência de discurso. Estes últimos não são comuns somente a esquizofrenia, mas às outras psicopatologias que também apresentam danos cerebrais frontais.

Assim como em outras psicopatologias, as causas, formas de diagnóstico e tratamento da esquizofrenia perpassam dois campos. Por um lado, têm-se hipóteses de cunho social e psíquico que abordam a partir de seus referenciais essa doença. Numa outra perspectiva, busca-se compreendê-la a partir de componentes biológicos. Neste artigo é reconhecida a validade de ambas as abordagens citadas e com a finalidade de demonstrar o impacto da epigenética sobre as psicopatologias, discorre-se inicialmente sobre os aspectos orgânicos da esquizofrenia e em seguida, sobre conteúdos que, de certo modo, vêm do ponto de vista do ambiente em que o indivíduo vive.

Uma das principais hipóteses sobre a causa da esquizofrenia, a partir do referencial biológico, é conhecida como hipótese dopaminérgica. Nessa presume-se que esse transtorno está ligado a uma hiperatividade do sistema dopaminérgico, o qual em condições normais de funcionamento é essencial a qualquer atividade humana, pois está envolvido por exemplo com o controle de movimentos, cognição, memória, humor e aprendizado. Já nessa hiperatividade, apresenta-se um desequilíbrio bioquímico que gera grande atividade sináptica dopaminérgica, o que explicaria muitos sintomas relacionados a essa doença. Nessa hipótese, compreende-se que esse modo de funcionamento, hiperativo ou não, possui aspectos relacionados aos genes. Entretanto, assume-se que isso não está relacionado a apenas um marcador genético, visto que ainda hoje não é possível definir um único gene relacionado a esse processo. Diante disso, o tratamento da esquizofrenia relaciona-se diretamente à prescrição de medicamentos para estabilizar o funcionamento das vias dopaminérgicas.

Por outro lado, há evidências de que determinadas substâncias que podem agir como agonistas ${ }^{1}$ dopaminérgicos. "Estas drogas incluem anfetamina, a cocaína, o metilfenidato (que bloqueia a recaptação de dopamina) e a DOPA (que estimula a síntese de dopamina)" (Carlson, 2002, p. 530). Ainda que isto esteja associado à hipótese dopaminérgica, é necessário evidenciar que nesse caso não se trata de predisposição genética, mas de fatores ambientais os quais um sujeito pode, ou não, ser exposto. Dessa forma, pode-se compreender que fatores externos - ambientais - podem também influir sobre o funcionamento de um organismo e causar esses desequilíbrios funcionais que podem acarretar a manifestação de psicopatologias.

Outras hipóteses buscaram noutras esferas as explicações para a esquizofrenia. Explicações relativas à fisiologia neuronal e seus padrões de funcionamento (Uhlhaas \& Singer, 2010), alterações morfofisiológicas na glia, nos neurônios e nas relações entre

\footnotetext{
${ }^{1}$ Agonistas: substâncias químicas similares às substâncias fisiológicas que ao se ligarem-se no receptor celular produzem respostas destas células.
} 
estas células (Faludi \& Minirc, 2011; Kim e cols., 2015) ou mesmo correlações da genética clássica (Kim e cols. 2011). Apesar das inúmeras tentativas, em níveis de abordagem diferentes, ainda nos resta um longo caminho na compreensão das causas e no desenvolvimento de abordagens terapêuticas mais eficientes e com menos efeitos colaterais.

Neste sentido, alguns autores têm encarado a epigenética como um caminho auspicioso de abordagem à esquizofrenia. Estudos relacionando a interação "gene e ambiente" se mostraram promissores (Geoffroy, Etain \& Houenou, 2013), enquanto outros, mais específicos, apontam que possíveis diferenças de marcadores epigenéticos podem ser úteis na compreensão da esquizofrenia (Alelú-Paz e cols., 2016; Carlaga-Martinez, Saiz-Ruiz \& Alelú-Paz, 2016; Gavin \& Floriane, 2014).

Com base nas questões mencionadas previamente, acredita-se que existam genes marcadores de uma tendência ao desenvolvimento dessa doença que podem, ou não, serem expressos. E essa dependência se dá na relação entre a constituição gênica de um indivíduo e sua atuação no ambiente, em que estes se influenciam mutuamente. De acordo com os dados relatados abaixo, não se pode sobrepor um desses dois aspectos como principal influente, visto que:

"Se a esquizofrenia fosse uma simples característica produzida por um único gene, poderíamos esperar encontrar este distúrbio em, no mínimo, $75 \%$ de crianças de pai e mãe esquizofrênicos se o gene fosse dominante. Se ele fosse recessivo, todas as crianças de pai e mãe esquizofrênicos deveriam se tornar esquizofrênicas. Entretanto, a incidência observada é menor que 50\%, o que significa que vários genes estão envolvidos, ou que ter um "gene para a esquizofrenia" confere uma suscetibilidade para desenvolvê-la, estando o aparecimento da doença dependente de outros fatores" (Carlson, 2002, p. 529).

A partir de uma perspectiva psicológica que permeia o estruturalismo e o funcionalismo, pensar a Esquizofrenia, ou outras psicopatologias, a partir dessa relação entre genes e ambiente (epigenética) permite elaborar novas formas de atuação do psicólogo para promover a saúde do indivíduo, visto que se ampliam as possibilidades de intervenção e tratamento, além do entendimento sobre as causas desses transtornos.

\section{Conclusão}

Neste artigo descrevemos o processo histórico de formação do conhecimento e método científico e a forma como, a partir das novas concepções de ciência, o homem, os meios em que vive e as relações que são construídas por ele passaram a ser pensadas e estudadas. Como sequência surgiu a psicologia, com o emblema do que seria seu objeto de estudo, e se desenvolveu com base em duas de suas escolas, o estruturalismo e o funcionalismo. A epigenética, em congruência com esta última escola, converge aos objetivos da psicologia ao reiterar que a composição estrutural do sujeito e o ambiente que este se encontra estão em interação e constituem suas relações funcionais.

Então, com os conceitos que a epigenética carrega, a forma de se pensar as psicopatologias pode ser alterada considerando o ambiente e a composição genética do sujeito com importâncias equivalentes. Neste sentido a esquizofrenia foi a patologia escolhida para que estes conceitos fossem aplicados.

Os resultados desta revisão literária revelam que a prática do psicólogo ao utilizar essa perspectiva interacionista entre a constituição genética (estrutural) do indivíduo e as relações que este estabelece no ambiente em que vive, pode ampliar a compreensão sobre as psicopatologias, tanto em aspectos sobre a causa e diagnóstico destas, quanto no que diz respeito às formas de tratamento para permitir ao indivíduo afetado por esses transtornos, toda qualidade de vida e bem estar possível ao mesmo.

Na esquizofrenia, o sujeito é portador de genes que o pré-dispõem a tal patologia, e estes podem ser expressos ou não dependendo do ambiente que o circunda. A partir desta ideia é que se vê a possibilidade de encontro da psicologia com a epigenética, ou seja, de uma aproximação entre biológico e social, permitindo aventar abordagens terapêuticas diversas e multiprofissionais que incluem, mas não se restringem aos medicamentos, mas também consideram alterações em hábitos e comportamentos que envolvem o sujeito em suas necessidades fisiológicas e sociais.

Todo este estudo é considerado ainda recente (em um contexto histórico) porque embora a epigenética tenha surgido na década de 40, apenas a partir das décadas de 80 e 90 começamos a ter ferramentas para entendê-la em suas bases moleculares. Ainda há muito o que fazer no campo e certamente os próximos anos trarão estudos e descobertas que mudarão a maneira como vemos diversas campos das ciências da saúde, biológicas e humanas. Optamos por destacar neste artigo dados que propõem uma alternativa, ainda em crescimento, ao determinismo biológico muitas vezes exposto sobre as psicopatologias. Trazer o sujeito pleno - estrutural e social - é uma das premissas da Psicologia e da praxis psi e acreditamos que este olhar contribui para aumentar a qualidade de vida do sujeito, trazendo responsabilidade e esperança por futuros melhores. 


\section{Referências}

Alelú-Paz, R. et al. (2016). Epigenetics in Schizophrenia: A Pilot Study of Global DNA Methylation in Different Brain Regions Associated with Higher Cognitive Functions. Journal Frontiersin. doi: https://doi.org/10.3389/fpsyg.2016.01496. http://journal.frontiersin.org/article/10.3389/fpsyg.2016.01496/full. Acesso em 20 de maio de 2017.

Araujo, S. F. (2007). Wilhelm Whundt e o estudo da experiência imediata. Em História da Psicologia: rumos e percursos, organizado por Ana Maria Jacó-Vilela, Arthur Arruda Leal Ferreira, Francisco Teixiera Portugal, 93-104. Rio de Janeiro: Nau Ed.

Bókkon, I. \& Mallic, B. N. (2016). Epigenetics and Neuro-behavioral Modulations". Current Neuropharmacology, 2016, Vol. 14, No. 1. 1-2. doi: 10.2174/1570159X1401160122124901.https://www.ncbi.nlm.nih.gov/pmc/articles/PMC4787281/. Acesso em 20 de maio de 2017.

Cariaga-Martinez, A. et al. (2016). From Linkage Studies to Epigenetics: What We Know and What We Need to Know in the Neurobiology of Schizophrenia. Frontiers in Neuroscience. Volume 10. Article 202. https://doi.org/10.3389/fnins.2016.00202 Acesso em 25 de julho de 2017.

Carlson, N. R. (2002). Fisiologia do Comportamento. Barueri: São Paulo.

Carneiro, H. A fabricação do vício. Anais do XIII Encontro Regional de História-Anpuh-MG, LPH-Revista de História, Departamento de História/ICHS/UFOP, Mariana-MG, no 12, 2002, pp. 9-24

Chaui, M. (1994). Convite à Filosofia. São Paulo: Editora Ática S. A.

Crews, D. (2008). Epigenetics and its implications for behavioral neuroendocrinology. National Institutes of Health. Front Neuroendocrinol. 2008 June; 29(3), 344-357. doi:10.1016/j.yfrne.2008.01.003 Acesso em 25 de julho de 2017.

Faludi, G. \& Mirnics, K. (2011). Synaptic changes in the brain of subjects with schizophrenia. International Journal of Developmental Neuroscience. 29(2011), 305-309. doi:10.1016/j.ijdevneu.2011.02.013

Fantappie, M. (2013). Epigenética e Memória Celular. Revista Carbono \#3. http://revistacarbono.com/artigos/03-epigenetica-ememoria-celular-marcelofantappie/. Rio de Janeiro: Acesso em 04 de abril de 2017.

Ferreira, A. L. \& Gutman, G. (2007). O funcionalismo em seus primórdios: a psicologia a serviço da adaptação. Em História da Psicologia: rumos e percursos, organizado por Ana Maria Jacó-Vilela, Arthur Arruda Leal Ferreira, Francisco Teixiera Portugal, 121-140. Rio de Janeiro: Nau Ed.

Feuerstein, R., Feuerstein, R. S. e Falik, L. H. (2014). Além da inteligência: aprendizagem mediada e a capacidade de mudança do cérebro. Petrópolis: Vozes.

Fluentes, D. et al. (2014). Neuropsicologia teoria e prática. Porto Alegre: Artmed.

Freitas-Silva, L. R. \& Ortega, F. (2016). A determinação biológica dos transtornos mentais: uma discussão a partir de teses neurocientíficas recentes. Cad. Saúde Pública, Rio de Janeiro, 32(8), e00168115, ago, 2016. doi: http://dx.doi.org/10.1590/0102311X00168115. Acesso em 15 de abril de 2017

Freitas-Silva, L. R. \& Ortega, F. (2014). A epigenética como nova hipótese etiológica no campo psiquiátrico contemporâneo. Physis Revista de Saúde Coletiva, Rio de Janeiro, 24[3], 765-786, 2014. doi: http://dx.doi.org/10.1590/S010373312014000300006 . Acesso em 15 de abril de 2017.

Gebicke-Haerter, P. J. (2012). Epigenetics of Schizophrenia. Pharmacopsychiatry 2012; 45(Suppl. 1), S42-S48. http://dx.doi.org/10.1055/s-0032-1304652 Acesso em 25 de julho de 2017.

Geoffroy, P. A. et al. (2013). Gene x environment interactions in schizophrenia and bipolar disorder: evidence from neuroimaging. Frontiers of Psychiatry. Volume 4. Article 136. https://doi.org/10.3389/fpsyt.2013.00136 Acesso em 25 de julho de 2017.

Harris, R. A. \& Jenner, P. (2014). International Review Of Neurobiology. Amsterdam: Radarweg.

Kender, K. S. (2013). What psychiatric genetics has taught us about the nature of psychiatric illness and what is left to learn. Molecular Psychiatry (2013), 1-9. doi:10.1038/mp.2013.50 Acesso em 25 de julho de 2017. 
Keverne, E. B. et al. (2015). Epigenetic changes in the developing brain: Effects on behavior". PNAS. Vol 112. No 22. $6789-795$. http://www.pnas.org/content/112/22/6789 Acesso em 25 de julho de 2017.

Kim, I. H. et al. (2015). Spine pruning drives antipsychotic-sensitive locomotion via circuit constrol of striatal dopamine. Nature Neoroscience. 18, 883-891. doi:10.1038/nn.4015 Acesso em 25 de julho de 2017.

Kim, Y. et al. (2011). Schizophrenia Genetics: Where Next?. Schizophrenia Bulletin. vol. 37 no. 3 pp. 456-463, 2011. doi:10.1093/schbul/sbr031 Acesso em 25 de julho de 2017.

Kirkbride, J. B. et al. (2012). Prenatal nutrition, epigenetics and schizophrenia risk: can we test causal effects?. Europe PMC Funders Group. Epigenomics. 2012 June; 4(3), 303-315. doi:10.2217/epi.12.20 Acesso em 25 de julho de 2017.

Laville, C. \& Dionne, J. (2008). Manual de metodologia de pesquisas em ciências humanas. Editado por Belo Horizonte: Editora UFMG

Marconi, M. A. \& Makatos, E. M. (2003). Fundamentos da Metodologia Científica. São Paulo: Editora Atlas S. A.

McGowan, P. O. \& Roth, T. L. (2015). Epigenetic pathways through which experiences become linked with biology. Dev Psychopathol. 2015 May; 27(2),637-648. https:// www.ncbi.nlm.nih.gov/pmc/articles/PMC4489549/. Acesso em 20 de maio de 2017. doi: $10.1017 /$ S0954579415000206

Mahgoub M. \& Monteggia, L. M. (2013). Epigenetics and Psychiatry. The American Society for Experimental NeuroTherapeutics. Neurotherapeutics (2013) 10:734-74. doi: 10.1007/s13311-013-0213-6. https://www.ncbi.nlm.nih.gov/pmc/articles/PMC3805856/. Acesso em 20 de maio de 2017.

Motta, P. A. (2009). Genética humana: aplicada a psicologia e toda a área biomédica. Rio de Janeiro: Guanabara Koogan.

Nieto, S. J. et al. (2016). Don't worry; be informed about the epigenetics of anxiety. Pharmacology Biochemistry and Behavior. 146-147(2016), 60-72. https://doi.org/10.1016/j.pbb.2016.05.006 Acesso em 25 de julho de 2017.

Nestler, E. J. (2013). Epigenetic mechanisms of drug addiction. Elsevier. Neuropharmacology. 76(2014), $259-268$. https://doi.org/10.1016/j.neuropharm.2013.04.004. Acesso em 25 de julho de 2017.

Piaget, J. (2014). Seis estudos de psicologia. Tradução de Maria Alice Guimarâes D’ Amorim e Paulo Sérgio Lima Silva. Rio de Janeiro: Forense Universitária.

Portugal, F. T. (2007). Comparação e genealogia na psicologia inglesa no século XIX. Em História da Psicologia: rumos e percursos, organizado por Ana Maria Jacó-Vilela, Arthur Arruda Leal Ferreira, Francisco Teixiera Portugal, 105-120. Rio de Janeiro: Nau Ed.

Präss, A. R. (2012). Teorias de aprendizado. ScriniaLibris.com. Press.

http://www.fisica.net/monografias/Teorias_de_Aprendizagem.pdf Acesso em 20 de maio de 2017.

Penã, C. J. et al. (2014). Epigenetic Signaling in Psychiatric Disorders. JMB molecular biology. YJMBI-64414; No. of pages: 24; 4C: 2, 3, 13. https://doi.org/10.1016/j.jmb.2014.03.016 Acesso em 25 de julho de 2017.

Read, A. \& Donnai, D. (2008). Genética Clínica: uma nova abordagem. 55-80. Porto Alegre: Artmed.

Ripoli, C. Engrampigenetics: Epigenetics of engram memory cells. Behavioural Brain Research doi: http://dx.doi.org/10.1016/j.bbr.2016.11.043. Acesso em 20 de maio de 2017.

Salvato, F., \& Labate, C. A. Epigenética. http://www.esalq.usp.br/departamentos/Ign/pub/seminar/FSalvato-200702-Resumo. Acesso em 15 de abril de 2017.

Stephen, M. Stahl, MD, PhD. (2009). Epigenetics and Methylomics in Psychiatry. J. Clin Psychiatry70:9, 1204-1205. doi: 10.4088/JCP.09bs05563. Acesso em 20 de maio de 2017.

Tang, W. Y. \& Ho, S. M. (2007). Epigenetic reprogramming and imprinting in origins of disease. Rev Endocr Metab Disord. 2007 June ; 8(2), 173-182. doi:10.1007/s11154-007-9042-4. Acesso em 20 de maio de 2017.

Tow, J. (2014). Heal the mother, heal the baby: epigenetics, breastfeeding and the human microbiome. Breastfeeding Review 2014; 22(1), 7-9. https://www.ncbi.nlm.nih.gov/pubmed/24804518?report=abstract Acesso em 04 de abril de 2017. 


\section{Sobre os Autores}

Aydamari João Pereira Faria Junior (PhD) é professor no Departamento de Psicologia do Instituto de Ciências Humanas e Sociais da Universidade Federal Fluminense, Brasil. Doutor em Fisiologia.

Ana Raquel Mendes de Toledo Neris é Aluna do Departamento de Psicologia do Instituto de Ciências Humanas e Sociais da Universidade Federal Fluminense, Brasil. Graduanda do curso de Psicologia na Universidade Federal Fluminense - Volta Redonda/RJ.

lara Peixoto de Oliveira é aluna no Departamento de Psicologia do Instituto de Ciências Humanas e Sociais da Universidade Federal Fluminense, Brasil. Graduanda do curso de Psicologia na Universidade Federal Fluminense - Volta Redonda/RJ. 